\title{
Immunization of Rats with Cholinergic Neurons Induces Behavioral Deficits
}

\author{
Joab Chapman, Joram Feldon*, Gil Alroy and Daniel M. Michaelson \\ Department of Biochemistry, The George S. Wise Faculty of Life Sciences, \\ and \\ *Department of Psychology, Tel Aviv University, \\ Ramat Aviv 69978, Israel
}

\section{ABSTRACT}

We have previously shown that sera from patients with Alzheimer's disease (AD) contain a significantly high level of antibodies to the cell bodies (Perikarya; PK) but not to the nerve terminals (synaptosomes) of purely cholinergic neurons from the electric fish Torpedo. In the present study we examined the effect of repeated immunization of rats with either of these antigens for one year. Immunoblot studies revealed that sera of cholinergic PK immunized rats contained a high level of antibodies to cholinergic PK proteins, in particular to a 200 kilodalton protein, to which there are specifically high levels of antibodies in AD. Sera from rats immunized with cholinergic synaptosomes and from control rats contained very low levels of these antibodies. Behavioral studies performed one year after the initial immunization revealed that the cholinergic PK immunized rats were impaired in spatial learning and memory tasks (Morris swim test and T-maze alternation) when compared to control rats and that the synaptosome-immunized rats showed no such deficit. In contrast, the three groups performed similarly in general activity, active avoidance and conditioned emotional response tests. Further experiments revealed that the cholinergic PK immunized rats displayed a significant deficit in short term memory. The association of antibodies to cholinergic neurons with cognitive deficits in this rat model suggests that such antibodies may be involved in the pathogenesis of $\mathrm{AD}$.

\footnotetext{
Address correspondence to:

Daniel M. Michaelson

Department of Biochemistry

Tel Aviv University

Ramat Aviv

Israel 69978

Tel. 03-5459624
}

Key Words

Alzheimer's disease; antibodies; behavioral tests; acetylcholine; Torpedo.

\section{INTRODUCTION}

Alzheimer's disease (AD), the most common cause of dementia, is associated with degeneration of cholinergic neurons in the basal forebrain which provide most of the cholinergic input to the cortex and hippocampus $/ 7,33 /$. The severity of these degenerative changes correlates with the cognitive impairment in $\mathrm{AD} / 2 /$. The extent of the cholinergic deficit, its occurrence early in the disease, its correlation with the cognitive deficit in $\mathrm{AD} / 12 /$ and the known role of cholinergic mechanisms in higher cognitive functions, particularly memory $/ 1,18 /$, all indicate a central role for cholinergic degeneration in the pathogenesis of $\mathrm{AD}$.

Although the etiology and pathogenesis of the cholinergic degeneration in $\mathrm{AD}$ are not known /31/, several reports implicate immunological mechanisms $15,9,14,21,26,28,34,35,39 /$. We have recently shown that sera of AD patients contain antibodies (IgG) which bind to specific constituents of cholinergic neurons and that these antibodies bind to cholinergic cell bodies but not to cholinergic nerve terminals $/ 3 /$. This study employed as antigen the purely cholinergic electromotor neurons of the electric fish Torpedo which are chemically homogeneous and contain many constituents which cross react antigenically with human and other mammalian cholinergic preparations $/ 18,27,28,38 /$. Further immunoblot experiments revealed that the $\mathrm{AD}$ IgG's bind to a specific 200 kilodalton $(\mathrm{kD})$ protein in the cell bodies and axons of the Torpedo cholinergic neurons and that the presence of such antibodies is specific to $\mathrm{AD}$ 
somes (1 mg protein $/ \mathrm{ml}$ ) were heated to $95^{\circ} \mathrm{C}$ for 5 minutes in $100 \mathrm{mM}$ Tris buffer, $\mathrm{pH}=6.8$, which contained $1.8 \%$ SDS $(\mathrm{w} / \mathrm{v})$ and $3 \%$ mercaptoethanol (v/v). Polypeptides were separated by electrophoresis on $12 \times 15 \mathrm{~cm} 10 \%$ SDS-polyacrylamide gels $(50 \mu \mathrm{g}$ protein/lane) utilizing a Biorad Protean II Slab Cell (50 $\mathrm{mA}$ for 2.5 hours) $/ 17 /$. The separated polypeptides were then transferred electrophoretically to nitrocellulose membranes (Biorad Trans-blot Cell at $100 \mathrm{~V}$ for $2 \mathrm{~h}$ ) $/ 37 /$. Sera to be tested were incubated with the nitrocellulose sheets and the bound $\operatorname{IgG}$ was detected with peroxidase conjugated anti-rat IgG as previously described $/ 4 /$. The molecular weights of polypeptides on the SDS-polyacrylamide gels and following the immunoblot assay were determined from the position of marker proteins of known molecular weight. Proteins were visualized with either Coomassie Blue (SDS-polyacrylamide gels) or Ponceau S (nitrocellulose strips).

The behavioral tests are described in the order in which they were performed.

\section{Morris Swim Test}

Subjects: Eleven rats immunized with cholinergic PK, 11 rats immunized with cholinergic synaptosomes and 12 controls entered and completed the experiment.

Apparatus: The apparatus consisted of a large circular pool $(240 \mathrm{~cm}$ diameter $\times 45 \mathrm{~cm}$ high) filled with water to a depth of $30 \mathrm{~cm}$. The water was rendered opaque by the addition of 6 liters fresh milk. All parts of the pool not covered by water were painted white. A small white plastic platform $(10 \times 10 \mathrm{~cm})$ weighted down by a metal base was always present at the center of the southeast quadrant $30 \mathrm{~cm}$ from the wall of the pool. The platform was submerged $1 \mathrm{~cm}$ beneath the surface of the milky water and was not visible from just above water level. A variety of extra-maze cues surrounded the maze and were available for the rats to utilize in locating the escape platform.

Procedure: On each trial the rat was placed into the water close to and facing the wall of the pool in one of 4 equally spaced locations. The rat was allowed to swim freely in the pool until it found the platform, onto which it would promptly climb to escape from the water. If a rat failed to locate the platform within $120 \mathrm{sec}$, it was placed there by the experimenter. The intertrial interval was $30 \mathrm{sec}$, during which the rat remained on the platform. Each rat received 4 trials per day for 5 days. Within each block of four trials, the rat was released at each of the starting locations, but the sequence of locations was randomized across rats and days. On each trial the latency to escape onto the platform was measured by a stopwatch.

Data analysis: The times to reach the platform for each trial were subjected to logarithmic transformation to allow the use of an ANOVA. Data analysis included a main factor of treatment (cholinergic PK, cholinergic synaptosomes and control) and repeated measurements factors of days (5) and trials (4).

\section{Locomotor Activity}

Subjects: The subjects were the same used in the Moris swim test.

Apparatus and procedure: Locomotor activity was measured using three activity cages measuring $51 \times 24 \times 21 \mathrm{~cm}$. Animals crossings were detected by a Rockwell-Aim-65 microprocessor. Rats were individually placed in the cages for $50 \mathrm{~min}$ and their crossings were recorded every $5 \mathrm{~min}$. Thus for each subject 10 data points were taken. All testing was conducted between 9 a.m. and 5 p.m. The testing order of the three experimental groups was counterbalanced. Data were analyzed using an ANOVA with a main factor of treatment (cholinergic PK, cholinergic synaptosomes and controls) and a repeated measurements factor of 10 successive 5 min samples.

\section{Conditioned Emotional Response (CER)}

Subjects: Eleven rats immunized with cholinergic PK, 11 rats immunized with cholinergic synaptosomes, and 12 controls entered the experiment. Two rats immunized with cholinergic synaptosomes and 1 control rat died during the experiment and an additional 3 PK rats, 4 synaptosomes rats and 1 control rat failed to acquire the drinking response and were excluded from the test. Results of 8 rats immunized with cholinergic PK, 5 rats immunized with cholinergic synaptosomes, and 10 controls were therefore included in the analysis.

Apparatus: The apparatus consisted of two plastic test chambers set in a ventilated sound-insulated GrasonStadler Research Chest (Model 1101). The internal dimensions of each chamber were $15 \times 20 \times 17 \mathrm{~cm}$, as measured from the raised grid floor. The chambers were flat gray, with small holes drilled in the side for ventilation. A drinking bottle could be inserted into the chamber. When the bottle was not present, the 
hole was covered by a plastic lid. Licks were detected by a drinkometer circuit. The conditioned stimulus was a $5 \mathrm{~s}, 2.8 \mathrm{kHz}$ tone produced by a Sonalert module (Model SC628). The shock grid was made from stainless steel bars $0.25 \mathrm{~cm}$ in diameter with $1.5 \mathrm{~cm}$ intervals. Shock was supplied by a Grason-Stadler scrambled shock source (Model E 1064GS) set at $1 \mathrm{~mA}, 1 \mathrm{~s}$ duration). A Rockwell AIM-65 microprocessor was used for equipment programming and data recording.

Procedure: Rats were placed on a $23-\mathrm{h}$ water deprivation schedule one day prior to and throughout the experiment. The stages of the CER procedure were as follows: 1) Base-line. On each of the 10 days, rats were individually placed into the experimental chamber and allowed to make 600 licks. Each subject was then returned to its home cage and allowed access to water for $60 \mathrm{~min}$. 2) Conditioning. On day 11 (following the 10 base-line days), with the water bottle removed, each animal was given one tone-shock pairing. Tone parameters were $5 \mathrm{sec}$ duration and $2.8 \mathrm{kHz}$ (see apparatus). The $1 \mathrm{~mA}, 1 \mathrm{sec}$ shock immediately followed tone termination. The tone-shock pairing was given $5 \mathrm{~min}$ after the start of the session. After the pairing, animals were left in the experimental chamber for an additional $5 \mathrm{~min}$. 3) Test. On day 12 each animal was placed in the chamber and allowed to drink from the bottle. When the subject completed 90 licks the tone was presented. The tone continued until ten additional licks were completed. If the subject failed to complete the last ten licks within $300 \mathrm{sec}$, the session was terminated and a score of 300 was recorded. The times between licks $80-90$ and $90-100$ were recorded.

Data analysis: Two one way ANOVA were performed on the times between licks 80-90 (before the presentation of the conditioned stimulus) and the time to complete licks 90-100 (when the conditioned stimulus was presented).

\section{Avoidance}

Subjects: Eleven cholinergic PK rats, 9 cholinergic synaptosomes rats, and 11 controls entered the experiment. One cholinergic synaptosomes rat and 2 control rats died during the course of the experiment and their results were not included. Analysis was therefore performed on results from 11 rats immunized with cholinergic PK, 8 immunized with cholinergic synaptosomes, and 9 controls.

Apparatus: The two-way active avoidance apparatus consisted of four identical Campden Instruments shuttle boxes, measuring $48.5 \times 23 \times 20 \mathrm{~cm}$. The barrier between the two compartments of the box consisted of an aluminum wall, with a central inverted U-shaped gate $(10 \times 7 \mathrm{~cm})$. Each box was set in a ventilated, soundinsulated chest. The conditioned stimulus was a $5-\mathrm{sec}$, $2.8 \mathrm{kHz}$ tone produced by a Sonalert module (Model SC 628). Shock was supplied to the grid floor by a Campden Instruments scrambled shock generator (Model 521C) set at $1 \mathrm{~mA}$ intensity. A micro-Vax mini-computer was used for equipment programming and data recording.

Procedure: Each animal was placed in the shuttle box with the house lights on and received 20 avoidance trials, presented on a variable interval $60-\mathrm{sec}$ schedule ranging from 30 to $90 \mathrm{sec}$. Each avoidance trial started with a 5 -sec tone followed by a 30 -sec shock, the tone remaining on with the shock. If the animals crossed the barrier to the opposite compartment during the 5 -sec tone, the tone was terminated and no shock was delivered. A crossing response during shock terminated the tone and the shock. If the animal failed to cross during the entire tone-shock trial, the tone and the shock terminated automatically after $35 \mathrm{sec}$. The animals received 10 such days of avoidance acquisition.

Analysis: The 200 trials were divided into 10 days of 20 trials, and all analyses were carried out on the percentage of avoidance on each of the ten 20-trial blocks, with days as a repeated measurements factor.

\section{T-Maze Alternation}

Subjects: Eleven cholinergic PK rats, 8 cholinergic synaptosomes rats and 9 controls entered the experiment. In addition 2 cholinergic PK rats, 3 cholinergic synaptosomes rats and 2 control rats failed to acquire the running response and were excluded from the test. Analysis was therefore performed on results from 6 cholinergic PK rats, 4 cholinergic synaptosomes rats and 7 controls.

Apparatus: The T-maze was built of unpainted wooden planks $9.5 \mathrm{~cm}$ wide with an edge about $0.7 \mathrm{~cm}$ high along each side. The stem of the $\mathrm{T}$ was $80 \mathrm{~cm}$ long, and the cross-piece was $136 \mathrm{~cm}$ long. A guillotine door was located $34.5 \mathrm{~cm}$ from the beginning of the stem. At each end of the cross-piece was a hole, $3.8 \mathrm{~cm}$ in diameter and $0.7 \mathrm{~cm}$ deep, which served as a food cup. The maze was supported by legs $30 \mathrm{~cm}$ long, and placed on a table in a small, irregularly shaped room which contained a variety of other objects, and was illuminated by fluorescent ceiling lights. 
Procedure: Rats were handled daily for at least a week before the test. There were 5 days of pretraining. For the first 2 days, rats were placed on the maze in pairs for about $20 \mathrm{~min}$ with $45 \mathrm{mg}$ Campden Instruments food pellets scattered along the cross-piece, and with the guillotine door raised. For the next 2 days, the rats were placed on the maze singly for about $15 \mathrm{~min}$, with the majority of the food located in the food cups; the guillotine door was repeatedly raised and lowered. On the fifth day two food pellets were placed in each food cup. Each rat was placed at the beginning of the start arm twice, and allowed to go to each of the food cups and eat the food there.

During acquisition, the rats were given 8 trials each day, each consisting of two runs through the maze. On each trial four food pellets were placed in each food cup, and a wooden block was placed on one arm close to the choice point, blocking off the access to that arm. On the information run the rat was placed at the starting point, the guillotine door was raised, and the rat allowed to go to the available arm and eat the food there. No retracing was permitted. The rat was then picked up and returned to the starting point and the wooden block was removed. The choice run followed. The guillotine door was raised, and the rat permitted to choose between the two arms. The rat was deemed to have made a choice when it placed a back foot on the choice arm. After each choice, the wooden block was placed behind the rat so that no retracing or correction was allowed. If the rats chose the arm not visited on the forced run, it was allowed to eat the food and was then removed from the maze. If the other arm was chosen, the rat was confined to the arm for approximately $10 \mathrm{sec}$ and was then returned to its holding cage. The rats were tested in groups of 4 , with each rat having one trial in turn, giving a typical inter-trial interval of $2-5 \mathrm{~min}$, which was spent in a holding cage near the maze. The arm to which the rat was directed for the information run varied from trial to trial, with the constraints that the same arm was not used for more than two consecutive trials and that each arm was used an equal number of times on any day.

Data Analysis: The analysis consisted of an ANOVA performed on the mean daily correct choices of each animal and included one main factor of treatment (cholinergic PK, cholinergic synaptosomes and control) and a repeated measurements factor of days.

\section{RESULTS}

\section{Immunological Studies}

The levels of antibodies to homogenates of purified Torpedo cholinergic PK and to cholinergic synaptosomes in rats immunized with either cholinergic PK or cholinergic synaptosomes were determined by means of an enzyme linked immunoassay (ELISA) two months following the initiation of immunization. The level of anti-cholinergic PK antibodies in all the cholinergic PK immunized rats $(\mathrm{n}=10)$ was high with end titration points at serum dilations above $1: 12,800$. Half maximal antibody binding was obtained at serum dilutions of 1:1000. Rats immunized with cholinergic synaptosomes $(n=10)$ had high levels of anti-cholinergic synaptosomes antibodies with titration end points at sera dilutions above 1:25,600 and half maximal antibody binding at sera dilutions of 1:2000. Bimonthly measurements of the average levels of anti-cholinergic PK antibodies in the PK immunized rats and of anticholinergic synaptosomes antibodies in the synaptosomes immunized rats revealed that they did not vary significantly for up to one year. Thus, in both groups maximal antibody levels were already reached two months after the initial immunization. The anti-cholinergic PK and anti-cholinergic synaptosomes antibodies in sera of control rats were low at all time points and reached background levels at sera dilutions of less than $1: 2000$.

The Torpedo polypeptides against which the rat antibodies are directed were identified by means of immunoblot assays. Since we have previously shown that $\mathrm{AD}$ patients have high levels of antibodies to Torpedo cholinergic PK and not to cholinergic synaptosomes $/ 3,4 /$ the experiment focused on the characterization of the anti-Torpedo cholinergic PK antibodies in the immunized rats. Immunoblot results utilizing electrophoresed cholinergic PK as antigen and sera (dilution 1:500) of 4 rats immunized for a year with either cholinergic PK, cholinergic synaptosomes or adjuvant are presented in Figure 1. As can be seen IgG from rats immunized with cholinergic PK interacted with more antigens than did those of rats immunized with synaptosomes or those of control rats. Examination of the immunblots revealed that 3 cholinergic PK rats contained IgG which bound to a polypeptide of molecular mass of approximately 200 kilodalton $(\mathrm{kD})$, whereas none of the choli- 
nergic synaptosomes immunized rats and none of the control rats had such IgGs. In addition, the cholinergic PK rats contained IgG which bound to proteins with molecular masses of 20 and $26 \mathrm{kD}$ (Fig. 1). Examination of larger groups of rats revealed that 12 of 15 rats immunized with cholinergic PK had antibodies to the $200 \mathrm{kD}$ protein whereas only 2 of the 12 rats immunized with cholinergic synaptosomes and none of the 13 controls tested had any such antibodies.

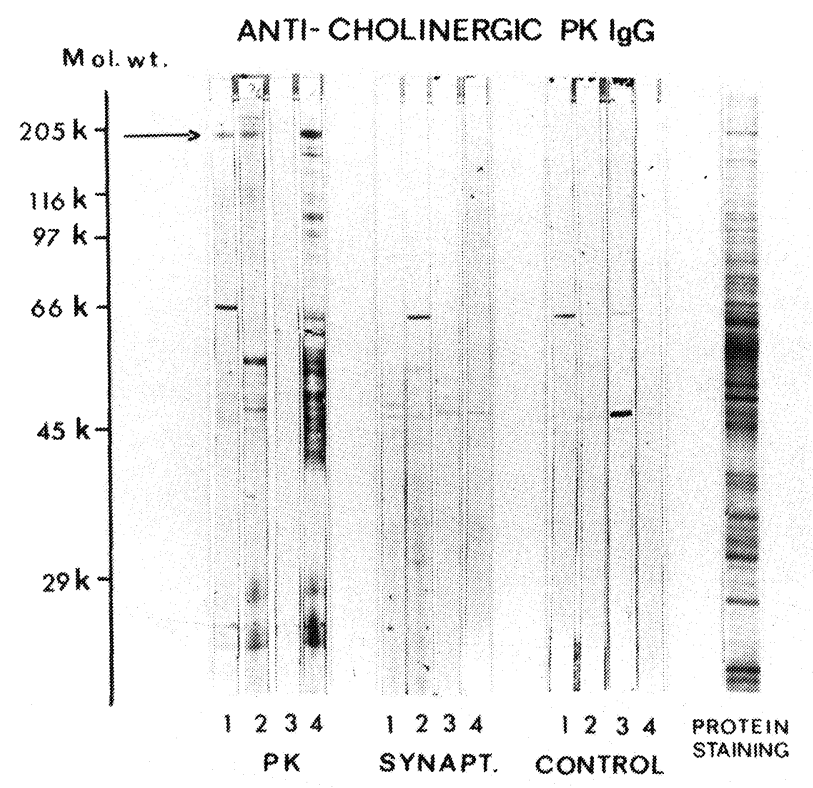

Fig. 1. Immunoblot assay of IgG directed against Torpedo cholinergic perikarya in sera of 4 rats immunized with cholinergic perikarya (PK), 4 rats immunized with Torpedo cholinergic synaptosomes (SYNAPT) and 4 control rats immunized with adjuvant alone. The assay was performed utilizing rat sera (dilution 1:500) and blots of electrophoresed Torpedo cholirergic perikarya as described in Experimental Procedures. The right lane is a coomassie blue stain of Torpedo cholinergic perikarya polypeptides following SDS-polyacrylamide gel electrophoresis. The molecular weight scale was generated utilizing marker proteins of known molecular weight.

Antibodies to the $200 \mathrm{kD}$ Torpedo cholinergic polypeptide are a prominent feature of sera from $\mathrm{AD}$ patients. We therefore excluded the small number of cholinergic PK rats with no such antibodies from the behavioral tests.

The three groups of rats weighed the same at the beginning of the experiment $[314 \pm 26,329 \pm 30$, and $318 \pm 31 \mathrm{~g}$ for respectively cholinergic PK, cholinergic synaptosomes and control rats; (mean $\pm \mathrm{SD})]$.
Their weight increased during the first 6 months following the initial immunization (respectively $509 \pm 38$, $509 \pm 35$ and $501 \pm 45 \mathrm{~g}$ ) and were virtually unchanged during the subsequent 8 months (respectively $532 \pm 48$, $535 \pm 51$ and $537 \pm 57 \mathrm{~g}$ ). An analysis of variance revealued no significant differences in the weights of the 3 treatment groups (F's $<1$ ), nor were any gross behavioral differences observed between these groups.

\section{Behavioral Studies}

The tests included place navigation in a Morris swim maze and a T-maze alternation test, both of which involve spatial memory tanks, a general motor activity paradigm, an active avoidance test and a conditioned emotional response test. The results of these tests are presented in the order in which they were performed.

\section{Morris Swim Test}

Fig. 2 presents the course of acquisition expressed as the daily mean $\log$ times for the 3 experimental groups (rats immunized with cholinergic $\mathrm{PK} \mathrm{n}=11$; Cholinergic synaptosomes $n=11$; and controls $n=12$ ).

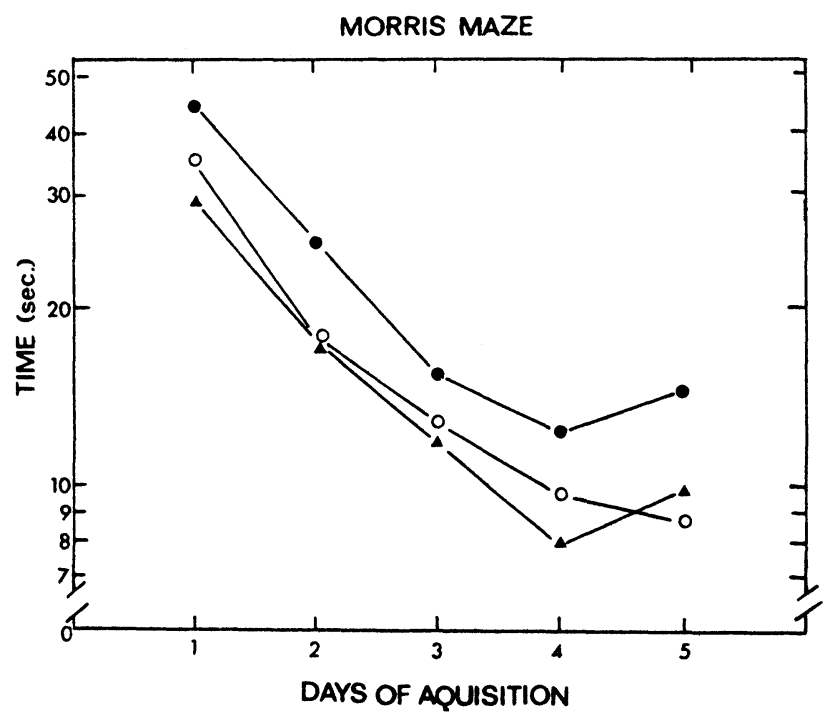

Fig. 2. Daily means (4 trials/day) of logarithmically transformed escape latencies in a Morris swim maze of rats immunized for a year with Torpedo cholinergic perikarya $(\bullet)(n=11)$, Torpedo cholinergic synaptosomes $(\boldsymbol{\Lambda})(\mathrm{n}=11)$ and adjuvant alone $(0)(\mathrm{n}=$ 13). 
As can be seen the 3 groups acquired the swimming response i.e. exhibited shorter response latencies as acquisition progressed. This was supported by the significant main effect of days $(F=44.43 \mathrm{df}=4 / 124$ $\mathrm{p}<0.001)$ and trials $(\mathrm{F}=12.46 \mathrm{df}=3 / 93 \mathrm{p}<0.001)$. Inspection of Fig. 2 also reveals that whereas the control and cholinergic synaptosomes groups acquired the response in a similar manner the cholinergic PK group was deficient throughout acquisition. This was supported by the significant main effect of treatment $(F=3.28 \mathrm{df}=2 / 31 \mathrm{p}=0.05)$. The main effect of treatment was not in interaction with either days or trials $(F ' s<1)$ indicating that a deficit existed throughout the acquisition phase.

\section{Locomotor Activity}

Figure 3 presents the mean number of crossings during successive 5 minute samples of the 50 minute session of the 3 treatment groups (cholinergic $\mathrm{PK}$, $\mathrm{n}=11$; cholinergic synaptosomes, $\mathrm{n}=11$; and controls, $\mathrm{n}=12$ ). As can be seen there was a significant decline in the number of crossings over the 10 sample periods which was supported by the significant main factor of samples $(F=100.27 \mathrm{df}=2 / 88 \mathrm{p}<0.001)$. However neither the main effect of treatment nor the interaction of treatment $\mathrm{x}$ sample were significant $(\mathrm{F}<1)$.

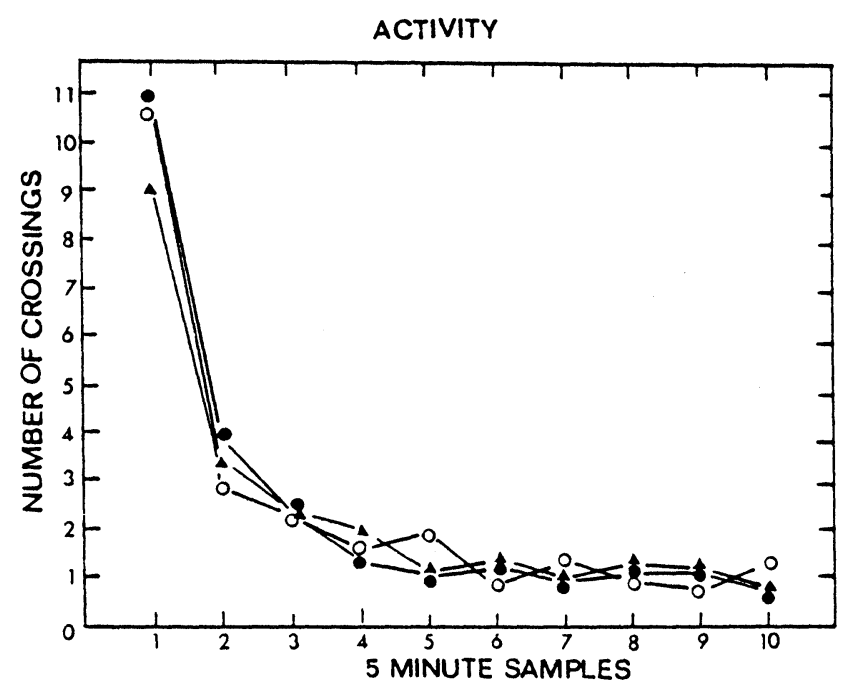

Fig. 3. Locomotor activity expressed as mean number of crossings during 10 five minute periods of rats immunized for a year with either Torpedo cholinergic perikarya $(\bullet)(n=11)$, Torpedo cholinergic synaptosomes $(\Delta)(n=11)$ or adjuvant alone $(0)(n=$ 13).

\section{Conditioned Emotional Response}

Table 1 summarizes the average times of the three groups (cholinergic PK, $\mathrm{n}=8$; cholinergic synaptosomes, $\mathrm{n}=5$; and controls, $\mathrm{n}=10$ ) to complete the 10 licks before and the 10 licks after the presentation of the conditioned stimulus. Analysis of the times to complete licks 80-90 (before the presentation of the conditioned stimulus) revealed a significant main effect of treatment $(F=4.03 \mathrm{df}=2 / 20 \mathrm{p}<0.04)$. This effect reflects the slower times of the rats immunized with cholinergic synaptosomes as compared with the control and cholinergic PK groups (Table 1).

TABLE 1

CONDITIONED EMOTIONAL RESPONSE OF RATS IMMUNIZED WITH TORPEDO CHOLINERGIC PERIKARYA, SYNAPTOSOMES AND CONTROLS

\begin{tabular}{lrrr}
\hline & Controls & $\begin{array}{l}\text { Cholinergic } \\
\text { Perikarya }\end{array}$ & $\begin{array}{l}\text { Cholinergic } \\
\text { Synaptosomes }\end{array}$ \\
\hline $\begin{array}{l}\text { Time to } \\
\text { complete } \\
\text { licks 80-90 }\end{array}$ & $2.06 \pm 0.72$ & $2.24 \pm 0.92$ & $4.06 \pm 2.58$ \\
$\begin{array}{l}\text { Time to } \\
\text { complete }\end{array}$ & & & \\
licks 90-100 & $109.14 \pm 133.9$ & $135.29 \pm 144.7$ & $103.97 \pm 121.77$
\end{tabular}

Rats were immunized for one year with purified cholinergic perikarya $(n=8)$, cholinergic synaptosomes $(n=5)$ and adjuvant (controls, $n=9$ ), after which they were subjected to a conditioned emotional response test performed as described in Experimental Procedures. Results presented are the mean time $\pm \mathrm{SD}$ for the 3 treatment groups to complete 10 licks before the conditioned stimulus (licks 80-90) and 10 licks during the conditioned stimulus (licks 90-100).

In contrast, no significant difference was observed between the three groups in the times to complete the 10 licks during the presentation of the conditioned stimulus $(\mathrm{F}<1)$.

\section{Avoidance}

As can be seen in Figure 4 all 3 groups (cholinergic $\mathrm{PK}, \mathrm{n}=11$; cholinergic synaptosomes, $\mathrm{n}=8$; and controls, $\mathrm{n}=9$ ) acquired the avoidance response over the 10 days of avoidance training. This was supported by the significant main effect of days $(F=9.42 \mathrm{df}=$ $9 / 225 \mathrm{p}<0.001)$. No differences were observed between the groups in acquisition of the avoidance re- 


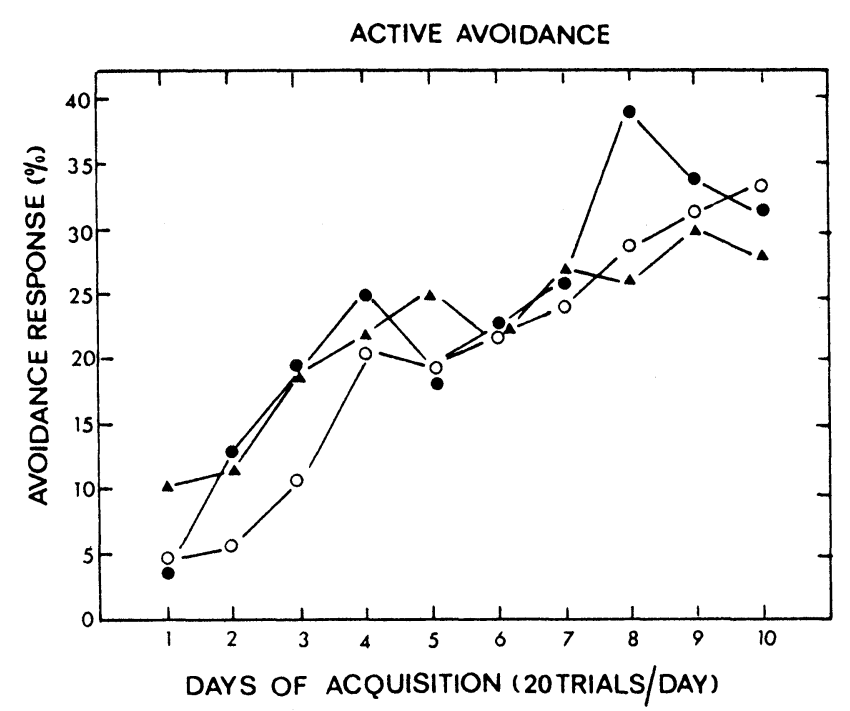

Fig. 4. Mean percent of avoidance responses over 10 days (20 trials/day) of rats immunized for a year with either Torpedo cholinergic perikarya $(\bullet)(n=11)$ Torpedo cholinergic synaptosomes $(\Delta) \quad(n=8)$ or adjuvant alone $(0)(n=9)$.

sponse in either the main effect of treatment or the interaction of treatment by days (F's $<1)$.

\section{T-maze Alternation}

The mean daily number of correct choices of the three groups (cholinergic $\mathrm{PK}, \mathrm{n}=6$; cholinergic synaptosomes, $n=4$; and controls, $n=7$ ) are presented in Fig. 5. As can be seen animals from all 3 groups exhibited improved performance as acquisition progressed. This was supported by the significant main effect of days $(F=11.32 \mathrm{df}=10 / 140 \mathrm{p}<0.001)$. However, the cholinergic PK group demonstrated a deficit relative to the other groups in choosing the correct arm on the choice trials. This deficit was evident throughout the entire course of acquisition and was supported by the significant main effect of treatment $(F=3.12 \mathrm{df}=2 / 14 \mathrm{p}<0.05)$. No difference was observed between the cholinergic synaptosomes group and the controls.

\section{EXPERIMENT 2}

The results presented in Experiment 1 suggest that rats immunized with cholinergic PK for one year acquire behavioral deficits in specific tasks involving spatial learning. In order to characterize the rate of development of this deficit and to examine whether

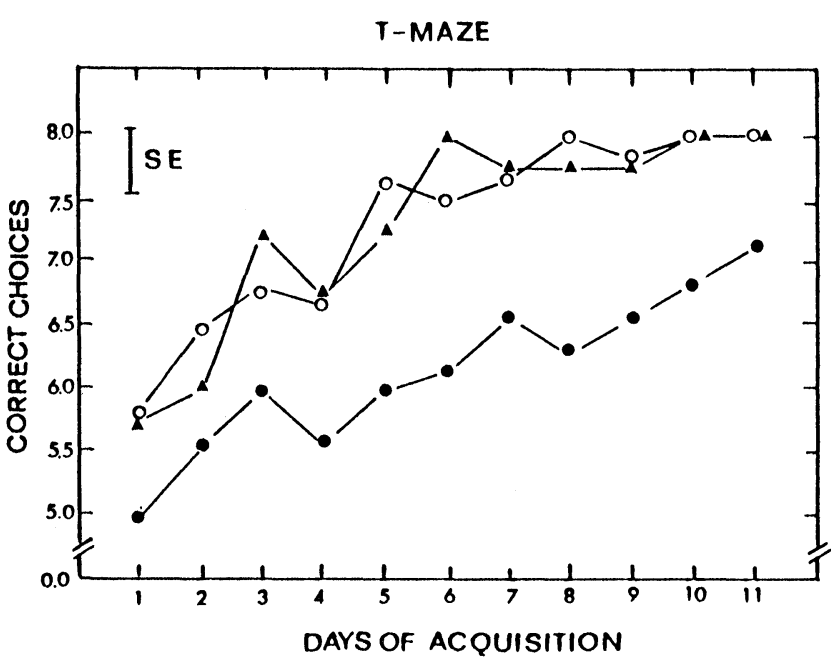

Fig. 5. Mean correct choices in a T-maze alternation test over 11 acquisition days (8 trials/day) of rats immunized for a year with either Torpedo cholinergic perikarya $(\bullet)(n=16)$, Torpedo cholinergic synaptosomes $(\boldsymbol{\Delta})(n=4)$ or adjuvant alone $(0)(n=$ 7). The SE bar represents one standard error derived from the term of the ANOVA.

it is accompanied by brain biochemical changes, a second group of rats was studied.

\section{EXPERIMENTAL PROCEDURES}

\section{Preparation of Antigens}

Torpedo cholinergic PK were prepared as described in Experiment 1.

\section{Subjects}

Male Sprague-Dawley rats were obtained and housed as described in Experiment 1. They were immunized subcutaneously at the age of 3 months with either Torpedo cholinergic PK $(50 \mu \mathrm{g}$ protein; $\mathrm{n}=32)$ or adjuvant alone (controls, $\mathrm{n}=32$ ). Further immunizations were given as in Experiment 1. At 4 and 8 months following the initial immunization immunoblot studies were performed with sera of 15 cholinergic PK immunized rats and 15 controls as described in Experiment 1. At each time point twelve of the cholinergic PK rats with a high level of antibodies to the $200 \mathrm{kD}$ PK protein and 12 control rats with no such antibodies were tested in the Morris swim maze. All the animals that were tested at 4 months completed the experiment whereas 2 controls died during the 8 months experiment and their results were excluded from the analysis. Nine cholinergic PK and 
9 control rats which completed the behavioral test at 4 months were sacrificed for the biochemical study which was performed at 6 months following the initial immunization. The rats which completed the Morris swim test at 8 months (10 cholinergic PK rats and 12 controls) were tested at 9 months in a T-maze alternation test. One rat in each group died during the course of the experiment and their results were excluded from the analysis. Nine rats from each group which completed the T-maze alternation test were sacrificed at 12 months for the biochemical study.

\section{Morris Swim Test}

The test was performed as described in Experiment 1 except that the analysis included only two groups in the main effect of treatment (Cholinergic PK and controls).

\section{T-maze Alternation}

The test was performed as described in Experiment 1 except that after the rats were tested for 10 days ( 8 trials per day) by this procedure they were further tested for 6 days in a modified paradigm. In this modified paradigm a $20 \mathrm{sec}$ delay was introduced between the information run and the test run. Analysis was performed separately on the two stages of the experiment (days 1-10 and 11-16) as in Experiment 1 except that only two groups were included in the main effect of treatment (Cholinergic PK and controls).

\section{Enzyme Activity Assays}

Groups of 9 cholinergic PK rats and 9 controls were sacrificed by cervical dislocation 6 months and 12 months following the initiation of immunization. Their brains were immediately excised and dissected into 10 areas: frontal cortex, parietal-occipital cortex, hippocampus, olfactory lobe, septum, striatum, hypothalamus, midbrain, cerebellum and brainstem. Each area was then homogenised $(10 \% \mathrm{w} / \mathrm{v})$ in ice cold $10 \mathrm{mM}$ phosphate buffer, $\mathrm{pH}=7.4$ and stored in aliquots at $-70^{\circ} \mathrm{C}$ until used.

Choline acetyltransferase (ChAT) activity was measured according to Fonnum /13/ whereas acetylcholinesterase (AChE) activity was assayed by the method of Johnson and Russel /15/. The levels of each enzyme in homogenates of brain areas of cholinergic PK and control rats were compared by Student's T test.
RESULTS

\section{Morris Swim Test}

The cholinergic PK rats and the controls acquired the swimming response at both 4 and 8 months following the initial immunization i.e. they exhibited shorter response latencies as acquisition progressed. This was supported by the significant main effect of days $(F=44.43 \mathrm{df}=4 / 124 \mathrm{p}<0.001$ at 4 months and $F=44.17 \mathrm{df}=4 / 76 \mathrm{p}<0.001$ at 8 months) and trials $(F=12.46 \mathrm{df}=3 / 93 \mathrm{p}<0.001$ at 4 months and $F=9.39 \mathrm{df}=3 / 57 \mathrm{p}<0.001$ at 8 months). The main effect of treatment in these experiments and in the Morris swim test performed in Experiment 1 (12 months) are summarized in Figure 6 which depicts the average log latencies of the different rat groups and the $p$ values of the main effect of treatment in each test. No difference was found between the cholinergic $\mathrm{PK}$ and the control rats at 4 months $(\mathrm{F}<1)$.

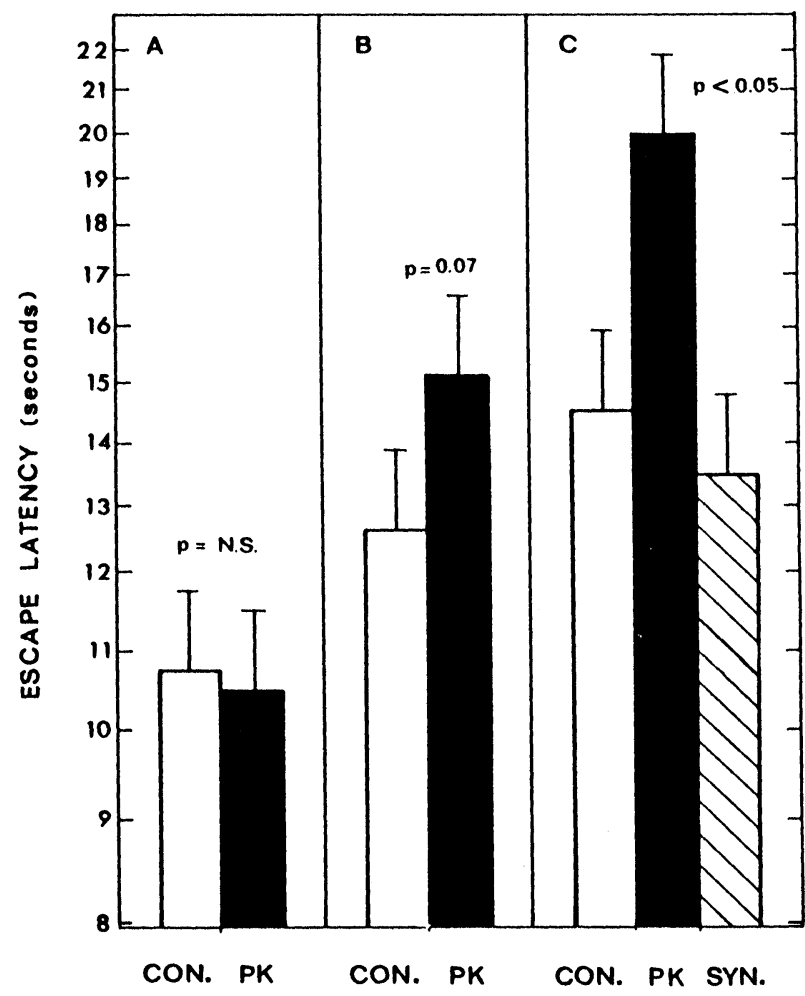

Fig. 6. The overall mean (over 5 training days) latencies to escape in a Morris swim test following 4 months (A), 8 months (B) and 12 months (C) of immunization of rats with Torpedo cholinergic perikayra (full bars), Torpedo cholinergic synaptosomes (striped bar) and adjuvant alone (open bars). 
At 8 months following the initiation of immunization the cholinergic PK rats displayed longer escape latencies than the controls $(F=3.55$, df $=1 / 19 p=0.07)$, and at 12 months they displayed significantly longer escape latencies $(F=3.28 \mathrm{df}=2 / 31 \mathrm{p}<0.05)$. The main effect of treatment was not in interaction with either days or trials in any of the swim tests performed (F's $<1$ ).

\section{T-maze Alternation Test}

The above water maze experiments suggest that the cholinergic PK rats display some degree of impaired performance after 8 months of immunization. In order to test whether their performance was also impaired in a T-maze alternation test at this time, the same animals were examined in this paradigm. This experiment was performed 9 months after the initial immunization. The daily average correct choices of the cholinergic PK $(n=11)$ and control $(n=9)$ groups over 16 days of acquisition are presented in Figure 7. As can be seen, both groups exhibited improved performance and achieved the same level of correct choices. This was supported by the significant main effect of days $(F=8.62 \mathrm{df}=9 / 162 \mathrm{p}<$ 0.001 ) and a non significant main effect of treatment $(\mathrm{F}<1)$. It should be noted that although it seems graphically that the cholinergic PK rats made fewer correct choices than the controls during the first 5 days of acquisition this difference was not statistically significant. In order to improve the sensitivity of the T-maze paradigm a 20 seconds delay was introduced on days 11 to 16 between the information and choice runs. As can be seen in Fig. 7 this delay caused a severe impairment in the performance of the cholinergic PK rats but had no effect on that of the controls. Analysis of the results obtained during the 6 days of acquisition following the introduction of the delay revealed a highly significant main effect of treatment $(\mathrm{F}=31.5 \mathrm{df}=1 / 18 \mathrm{p}<0.001)$.

\section{Biochemical Studies}

In order to examine whether the behavioral changes manifested by the cholinergic PK rats were accompanied by biochemical changes in their brains, we sacrificed 9 rats from each group (cholinergic PK and controls) at 6 and 12 months following the initiation of immunization and measured the weights, protein content and ChAT and AChE activities in define regions of their brains (frontal cortex, parietal-occi-

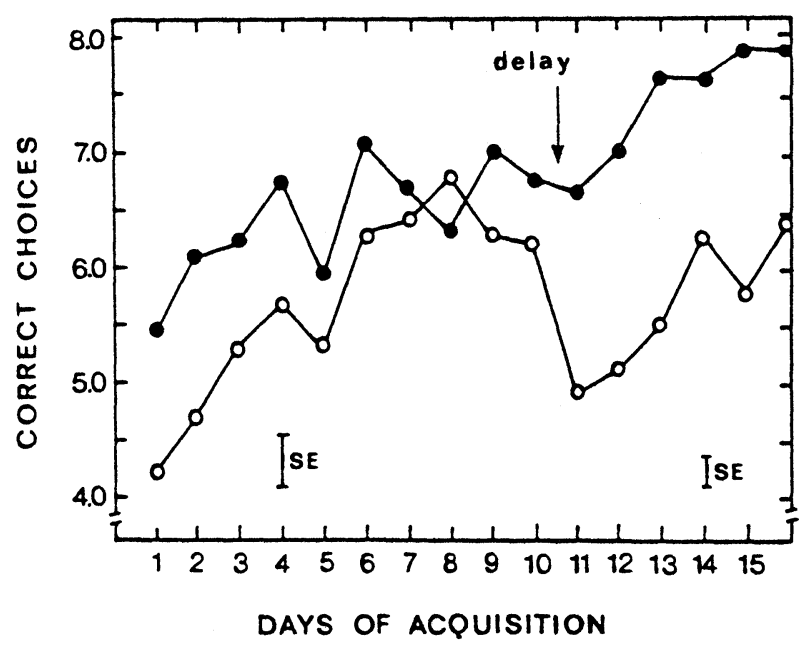

Fig. 7. Mean correct choices in a T-maze alternation test over 16 training days of rats immunized for 9 months with Torpedo cholinergic perikarya $(O)(n=11)$ and of control rats immunized with adjuvant alone (•) $(n=9)$. The delays between the information and choice runs were $0 \mathrm{sec}$ and $20 \mathrm{sec}$ on days $1-10$ and 11-16 respectively. The bars on the left and right hand sides of the figure represent one standard error derived from the error term of the ANOVA for days $1-10$ and $11-16$ respectively.

pital cortex, hippocampus, olfactory lobe, septum, striatum, hypothalamus, midbrain, cerebellum and brainstem). The ChAT and AChE levels thus measured are summarized in Table 2 and Table 3 respectively. As can be seen the levels of both enzymes in the hypothalamus of cholinergic PK rats increased significantly above the control level at 8 months (ChAT 23\%, p < 0.01 , AChE 19\%, p < 0.05), and decreased to levels below that of the controls at 12 months (ChAT 12\%, $\mathrm{p}<0.05, \mathrm{AChE} 5 \%$, not significant). No significant changes were observed in the ChAT activity of the other brain areas examined. The levels of AChE activity in the septum of cholinergic PK immunized rats increased by $21 \%(\mathrm{p}<0.05)$ at 6 months and returned to control levels at 12 months. Additional statistically significant changes in AChE levels of the cholinergic PK rats were observed at 12 months in the hippocampus and striatum (a decrease of about $10 \%, \mathrm{p}<0.05$ ) and in the olfactory lobe (an increase of $34 \% ; \mathrm{p}<0.05)$. The ChAT and AChE levels in the midbrain, cerebellum and medulla-pons of cholinergic PK rats did not differ at any time from those of controls. No differences were observed between the weights and protein contents of brain areas of the cholinergic $\mathrm{PK}$ and control rats. 
TABLE 2

THE EFFECTS OF IMMUNIZATION WITH TORPEDO

CHOLINERGIC CELL BODIES ON RAT BRAIN CHOLINEACETYLTRANSFERASE LEVELS

\begin{tabular}{|c|c|c|c|c|}
\hline & \multicolumn{2}{|c|}{$\begin{array}{l}\text { six months } \\
\text { immunization }\end{array}$} & \multicolumn{2}{|c|}{$\begin{array}{l}\text { twelve months } \\
\text { immunization }\end{array}$} \\
\hline & $\begin{array}{l}\text { control } \\
\text { rats } \\
(\mathrm{pmol} / \mathrm{mg} \\
\text { protein } / \mathrm{min})\end{array}$ & $\begin{array}{c}\text { PK } \\
\text { rats } \\
\text { (\% of } \\
\text { control) }\end{array}$ & $\begin{array}{l}\text { control } \\
\text { rats } \\
\text { (pmol/mg } \\
\text { protein } / \mathrm{min})\end{array}$ & $\begin{array}{c}\text { PK } \\
\text { rats } \\
\text { (\% of } \\
\text { control) }\end{array}$ \\
\hline hippocampus & $458 \pm 41$ & $97 \pm 9$ & $587 \pm 59$ & $98 \pm 5$ \\
\hline septum & $1099 \pm 154$ & $113 \pm 15$ & $1043 \pm 125$ & $105 \pm 15$ \\
\hline hypothalamus & $293 \pm 25$ & $123 \pm 18 * *$ & $389 \pm 48$ & $88 \pm 7^{*}$ \\
\hline posterior cortex & $414 \pm 41$ & $103 \pm 15$ & $471 \pm 42$ & $102 \pm 14$ \\
\hline frontal cortex & $346 \pm 35$ & $110 \pm 30$ & $428 \pm 30$ & $99 \pm 14$ \\
\hline olfactory lobe & $520 \pm 114$ & $95 \pm 28$ & $699 \pm 125$ & $90 \pm 29$ \\
\hline striatum & $1325 \pm 132$ & $118 \pm 25$ & $1226 \pm 122$ & $100 \pm 12$ \\
\hline midbrain & $506 \pm 35$ & $107 \pm 9$ & $503 \pm 50$ & $108 \pm 8$ \\
\hline cerebellum & $94 \pm 13$ & $103 \pm 15$ & $78 \pm 6$ & $94 \pm 14$ \\
\hline medulla-pons & $876 \pm 44$ & $102 \pm 11$ & $1020 \pm 61$ & $98 \pm 10$ \\
\hline
\end{tabular}

The levels of cholineacetyltransferase in brain areas of groups of rats immunized for either six or twelve months with cholinergic cell bodies (PK rats) or adjuvant (control rats) were measured as described in Experimental Procedures. Results presented are the mean \pm SD of 9 rats in each group. The values of the cholinergic PK rats (mean \pm SD) are expressed as $\%$ of the corresponding control values.

$* \mathrm{p}<0.05, \quad * * \mathrm{p}<0.01$.

\section{DISCUSSION}

The central clinical feature of $\mathrm{AD}$ is dementia. Thus, any animal model attempting to replicate features of the disease should display some behavioral deficits. The present findings show that rats immunized for one year with isolated perikarya of the purely cholinergic Torpedo neurons display behavioral changes. The cognitive deficits observed were apparent in the Morris swim test and T-maze alternation test, both of which monitor performance in spatial learning tasks. In contrast, these rats showed no impairment in general locomotor activity, in a conditioned emotional response paradigm and in an active avoidance test. These findings suggest that immunization with PK induces specific cognitive deficits.

Introduction of a $20 \mathrm{sec}$ delay in the T-maze alternation test 9 months after the initiation of immunization uncovered a marked deficit in the performance of the cholinergic PK immunized rats (Fig. 7). This finding suggests that the behavioral deficit is due to a specific derangement of short term memory
TABLE 3

THE EFFECTS OF IMMUNIZATION WITH TORPEDO CHOLINERGIC CELL BODIES ON RAT BRAIN ACETYLCHOLINESTERASE LEVELS

\begin{tabular}{|c|c|c|c|c|}
\hline & \multicolumn{2}{|c|}{$\begin{array}{l}\text { six months } \\
\text { immunization }\end{array}$} & \multicolumn{2}{|c|}{$\begin{array}{c}\text { twelve months } \\
\text { immunization }\end{array}$} \\
\hline & $\begin{array}{l}\text { control } \\
\text { rats } \\
\text { (pmol/mg } \\
\text { protein/min) }\end{array}$ & $\begin{array}{c}\text { PK } \\
\text { rats } \\
\text { (\% of } \\
\text { control) }\end{array}$ & $\begin{array}{l}\text { control } \\
\text { rats } \\
\text { (pmol/mg } \\
\text { protein } / \mathrm{min} \text { ) }\end{array}$ & $\begin{array}{c}\text { PK } \\
\text { rats } \\
(\% \text { of } \\
\text { control) }\end{array}$ \\
\hline hippocampus & $49 \pm 5$ & $102 \pm 12$ & $51 \pm 4$ & $91 \pm 7 *$ \\
\hline septum & $89 \pm 8$ & $121 \pm 20^{*}$ & $83 \pm 11$ & $105 \pm 23$ \\
\hline hypothalamus & $55 \pm 4$ & $119 \pm 17^{*}$ & $65 \pm 7$ & $95 \pm 9$ \\
\hline posterior cortex & $32 \pm 3$ & $97 \pm 14$ & $36 \pm 3$ & $91 \pm 14$ \\
\hline frontal cortex & $31 \pm 2$ & $101 \pm 11$ & $33 \pm 3$ & $90 \pm 12$ \\
\hline olfactory lobe & $48 \pm 10$ & $88 \pm 22$ & $36 \pm 5$ & $134 \pm 29 *$ \\
\hline striatum & $250 \pm 33$ & $112 \pm 24$ & $263 \pm 24$ & $88 \pm 6^{*}$ \\
\hline midbrain & $70 \pm 6$ & $105 \pm 9$ & $71 \pm 6$ & $99 \pm 8$ \\
\hline cerebellum & $23 \pm 3$ & $100 \pm 12$ & $24 \pm 3$ & $104 \pm 15$ \\
\hline medulla-pons & $61 \pm 3$ & $97 \pm 9$ & $73 \pm 7$ & $104 \pm 13$ \\
\hline
\end{tabular}

The levels of acetylcholinesterase in brain areas of groups of rats immunized for either six or twelve months with cholinergic cell bodies (PK rats) or adjuvant (control rats) were measured as described in Experimental Procedures. Results presented are the mean \pm SD of 9 rats in each group. The values of the cholinergic PK rats (mean \pm SD) are expressed as $\%$ of the corresponding control values.

$* \mathrm{p}<0.05$.

associated with spatial localization. It is interesting to note that a similar delay dependent deficit in short term memory has been demonstrated in patients with $\mathrm{AD} / 30 /$ and that spatial localization is also impaired in this disease /22/. Furthermore, animal models of AD involving lesions of the cholinergic nuclei of the basal forebrain likewise produce spatial localization deficits and a working memory deficit indicative of a decreased short term memory $/ 38 /$.

The rats developed a maximal immunological response to the cholinergic PK antigens after 2 months of immunization. In contrast, examination of the rate of onset of the deficit in the Morris swim test of immunized rats revealed no behavioral deficit at 4 months, a detectable impairment at 8 months and a significant deficit after 12 months of immunization (Fig. 6). A similar time course was observed in the performance of rats in a T-maze alternation test. The rats immunized for 9 months showed only a small and insignificant deficit in performing the test while those immunized for 14 months displayed a clear deficit in the same paradigm (Figs. 5 and 7). It thus 
seems that the behavioral deficits develop at a substantially slower rate than the immunological response to the cholinergic PK antigens. This finding may be due to the greater susceptibility of older rats to an immune mediated insult or may indicate the slowly progressive nature of this insult. Previous studies on the entry of IgG into normal rat brain have indicated that this is indeed a relatively slow process dependent on retrograde axonal transport /10, 24/. The relevance of this mechanism to the present findings and the influence of other mechanisms on the rate of development of the cognitive deficit remain to be determined.

The finding that the behavioral deficits are induced by immunization with Torpedo cholinergic PK but not with the purified nerve terminals of the same neurons suggests that these deficits are due to an immune response specific to Torpedo cholinergic PK. Examination of the antibodies specific to rats immunized with cholinergic PK revealed antibodies to three antigens with apparent molecular weights of respectively 20, 26, and $200 \mathrm{kD}$. Neither rats immunized with cholinergic synaptosomes nor the control rats developed antibodies to these antigens (Fig. 1). Some evidence exists to indicate that, of these three antigens, the immune response to the $200 \mathrm{kD}$ protein is relevant to the cognitive deficit. Firstly, immunization of another strain of rats (Wistar) with Torpedo cholinergic $\mathrm{PK}$ resulted in production of antibodies to the 20 and $26 \mathrm{kD}$ polypeptides but not to the $200 \mathrm{kD}$ protein and did not cause any apparent deficit in performance in a T-maze alternation test (not shown). Secondly, AD patients also have specific antibodies which bind to the $200 \mathrm{kD}$ protein of Torpedo cholinergic PK but not antibodies to the 20 and $26 \mathrm{kD}$ polypeptides $/ 4 /$. The hypothesis that the observed cognitive deficits are due to a specific immune reaction to the Torpedo cholinergic $200 \mathrm{kD}$ protein is currently being investigated in our laboratories by experiments in which rats are immunized for a prolonged period with the purified protein and the resulting immunological and behavioral responses are examined.

The cellular and biochemical mechanisms underlying the immunologically induced behavioral changes in the rats are not known. The findings that ChAT and AChE levels change in some brain areas show that the central nervous system, and in particular central cholinergic neurons are affected by the immunization. It is interesting to note that not all central cholinergic neurons seem affected. The midbrain, cerebellum and brainstem, areas which are relatively preserved in $\mathrm{AD}$, show no biochemical changes following immunization of the rats with cholinergic PK. Biochemical changes were found in the septum, hippocampus, striatum (which in the rodent contains the equivalent of the nucleus basalis of Meynert), cortex and hypothalamus of the PK immunized rats. These areas are involved in learning and memory and have all been reported to be affected in the brains of $\mathrm{AD}$ patients. It should be noted that in some of these brain areas (e.g. hypothalamus and septum) the decrease in enzymatic activity observed after one year was preceded by a transient increase (see Tables 2 and 3). Increases of ChAT activity per cholinergic neuron in the nucleus basalis of Meynert and in AChE activity in the cortex have previously been observed in $\mathrm{AD}$ patients $/ 40 /$. It is important however to stress that the nature and extent of the changes in ChAT and $\mathrm{AChE}$ activities reported in the present study are unlike the profound reduction in ChAT activity found in the brains of $\mathrm{AD}$ patients. It remains to be seen whether the presently observed neurochemical changes in the brains of the immunized rats represent an early phase of a pathogenetic process similar to $\mathrm{AD}$ and whether immunization for more than one year will induce more severe biochemical as well as histological changes and the extent of their similarity to those found in $\mathrm{AD}$.

In summary, the findings presented show that rats immunized with cholinergic PK gradually develop behavioral deficits and impairments in short term memory. These findings indicate that immunization with cholinergic PK antigens induces specific brain neuronal dysfunction in rats and support the provocative hypothesis that the antibodies to cholinergic antigens found in patients with $\mathrm{AD}$ may also play a role in the degeneration of central cholinergic neurons in this disease.

\section{ACKNOWLEDGEMENTS}

We thank Yaakov Egozi for invaluable advice and technical assistance and Eli Ben-Zaken for help with the performance of some of the behavioral tests. The cooperation and assistance of Dr. Naam Kariv and Ilana Yosef is gratefully acknowledged. Preliminary studies were performed with the generous help of Dr. Eti Grauer and Shirry Chapman. This work was supported in part by a grant to D.M.M. from the Esterson Trust and by a Foulkes Foundation Fellowship to J.C. 


\section{REFERENCES}

1. Bartus RT, Dean RL, Beer B, Lippa AS. The cholinergic hypothesis of geriatric memory dysfunction. Science 1982; 217: 408-417.

2. Blessed G, Tomlinson BE, Roth M. The association between quantitative measures of dementia and of senile change in the cerebral grey matter of elderly subjects. Br J Psychiatry 1968; 114: 797-811.

3. Chapman J, Korzcyn AD, Hareuveni M, Michaelson DM. Antibodies to cholinergic cell bodies in Alzheimer's disease. In A. Fisher, I. Hanin and C. Lachman (Eds.), Alzheimer's and Parkinson's Diseases, Plenum Publishing Corporation, New York, 1986, p. 329-336.

4. Chapman J, Bachar O, Korczyn AD, Wertman E, Michaelson DM. Antibodies to cholinergic neurons in Alzheimer's disease. J Neurochem 1988; 51: 479-485.

5. Cameron DJ. Isolation of two unique fractions from the cerebrospinal fluid of Alzheimer disease patients. Japan J Exp Med 1985; 55: 177-183.

6. Colton T. Statistics in Medicine. Little, Brown and Co., Boston, 1974, $372 \mathrm{pp}$.

7. Coyle JT, Price DL, DeLong MR. Alzheimer's disease: a disorder of cortical cholinergic innervation. Science 1983; 219: 1184-1190.

8. Dowdall MJ, Fox G, Wachtler K, Whittaker VP, Zimmermann $\mathrm{H}$. Recent studies on the comparative biochemistry of the cholinergic neuron. Cold Spring Harbour Symposium on Quantitative Biology 1976; XL: 65-81.

9. Eikelenboom P, Stam FC. Immunoglobulins and complement factors in senile plaques. An immunoperoxidase study. Acta Neuropath (Berl.) 1982; 57: 239-242.

10. Fabian RH, Petroff G. Intraneuronal IgG in the central nervous system: uptake by retrograde axonal transport. Neurology 1987; 37: 1780-1784.

11. Fillit H, Luine VN, Reisberg B, Amador R; Mcewen B, Zabriske JB. Studies of the specificity of antibrain antibodies in Alzheimer's disease. In J.T. Hutton and A.D. Kenny (Eds.), Senile Dementia of the Alzheimer Type. Alan Liss, New York, 1985, pp. 307-318.

12. Francis PT, Palmer AM, Sims NR, Bowen DM, Davison AM, Esiri MM, Neary D, Snowden JS, Wilcock GK. Neurochemical studies of early-onset Alzheimer's disease; possible influence on treatment. New Engl J Med 1985; 313: 7-11.

13. Fonnum F. A rapid radiochemical method for the determination of choline acetyltransferase. J Neurochem 1975; 24: 407-409.

14. Ishii $\mathrm{T}$, Haga $\mathrm{S}$. Immuno-electron microscopic localization of immunoglobulins in amyloid fibrils of senile plaques. Acta Neuropath (Berl.) 1976; 36: 243-249.

15. Johnson CD, Russel RL. A rapid simple radiometric assay for cholinesterase suitable for multiple determinations. Anal Biochem 1975; 64: 229-238.

16. Kushner PD. A library of monoclonal antibodies to Torpedo cholinergic synaptosomes. J Neurochem 1984; 43: 775-786.

17. Laemmu UK. Cleavage of structural proteins during assembly of the head of bacteriophage T4. Nature 1970; 227: 680-685.
18. Levin Y, Elizur A, Korczyn AD. Physostigmine improves ECT-induced memory disturbances. Neurology 1987; 37: 871-875.

19. Lowry OH, Rosebrough NJ, Farr AL, Randall RJ. Protein measurement with the Folin phenol reagent. J Biol Chem 1951; 193: 285-275.

20. Markwell MAK, Haas SM, Neiber LC, Talbert NE. A modification of the Lowry procedure to simplify protein determination in membrane and lipoprotein samples. Anal Biochem 1978; 87: 206-210.

21. McGeer PL, Itagaki S, Tago H, McGeer EG. Reactive microglia in patients with senile dementia of the Alzheimer type are positive for the histocompatibility glycoprotein HLA-DR. Neurosci Lett 1987; 79: 195-200.

22. McKhann G, Drachman D, Folstein M, Katzman R, Price D, Stadlan EM. Clinical diagnosis of Alzheimer's disease. Neurology 1984; 34: 939-944

23. McRae-Degueurce A, Booj S, Haglid K, Rosengren L, Karlsson JE, Karlsson I, Wallin A, Svenerholm L, Gottfries CG, Dahlstrom A. Antibodies in cerebrospinal fluid of some Alzheimer disease patients recognize cholinergic neurons in the rat central nervous system. Proc Natl Acad Sci USA 1987; 84: 9214-9218.

24. Meeker ML, Meeker RB, Hayward JN. Accumulation of circulating endogenous and exogenous immunoglobulins by hypothalamic magnocellular neurons. Brain Research 1987; 423: 45-55.

25. Michaelson DM, Sokolovsky M. Induced acetylcholine release from active purely cholinergic Torpedo synaptosomes. J Neurochem 1978; 30: 217-230.

26. Nandy K. Brain-reactive antibodies in aging and senile dementia. In R. Katzman, R.D. Terry and K.L. Bick (Eds.), Alzheimer's Disease: Senile Dementia and Related Disorders. Aging. Vol. 7, Raven Press, New York, 1978, pp. 503-511.

27. Patrick J, Lindstrom J. Autoimmune response to acetylcholine receptors. Science 1973; 180: 871-879.

28. Pouplard-Barthelaix A, Dubas F, Maher I, Jabbour W, Emile J. Expression of HLA-DR (MHC class II molecules) in the brain: "In situ" demonstration of immunologic mechanisms in Alzheimer's disease (AD, SDAT). Neurology 1987; 37 (Suppl 1): 225.

29. Richardson PJ, Walker JH, Jones T, Whittaker VP. Identification of a cholinergic-specific antigen Chol-1 as a ganglioside. J Neurochem 1982; 38: 1605-1614.

30. Sahakian BJ, Morris RG, Evenden JL, Heald A, Levy R, Philpot M, Robbins TW. A comparative study of visuospatial memory and learning in Alzheimer-type dementia and Parkinson's disease. Brain 1988; 111: 695-718.

31. Schmidt G. Mechanisms and possible causes of Alzheimer's disease. Postgrad Med 1983; 73: 206-213.

32. Shek PN, Howe SA. A novel method for the rapid bleeding of rats from the tail vein. $\mathbf{J}$ Immunol Methods 1982; 53: $255-260$.

33. Sims NR, Bowen DM, Allen SJ, Smith CCT, Neary D, Thomas DJ, Davison AN. Presynaptic cholinergic dysfunction in patients with dementia. J Neurochem 1983; 40: 503-509.

34. Singh VK, Fudenberg HH, Brown FR. Immunologic dys- 
function: simultaneous study of Alzheimer's and older Down's patients. Mech Ageing Dev 1987; 37: 257-264.

35. Skias D, Reder A, Bania M, Antel J. Immune regulation in aging and senile dementia of Alzheimer type (SDAT). Neurology 1985; 35 (Suppl 1): 217.

36. Smith G. Animal models of Alzheimer's disease: experimental cholinergic denervation. Brain Research Rev 1988; 13: $103-118$.

37. Towbin H, Staehlin T, Gordon J. Electrophoretic transfer of proteins from polyacrylamide gels to nitrocellulose sheets: procedures and some applications. Proc Natl Acad Sci USA $1979 ; 76$ : 4350-4354.
38. Walker JH, Jones RT, Obrocki J, Richardson GP, Stadler H. Presynaptic plasma membranes and synaptic vesicles of cholinergic nerve endings demonstrated by means of specific antigens. Cell Tissue Res 1982; 223: 101116.

39. Watts H, Kennedy PGE, Thomas M. The significance of anti-neuronal antibodies in Alzheimer's disease. J Neuroimmunol 1981; 1: 107-116.

40. Younkin SG, Goodridge B, Katz J, Lockett G, Nafziger D, Usiak MF, Younkin LH. Molecular forms of acetylcholinesterases in Alzheimer's disease. Federation Proc 1986; 45: 2982-2988. 

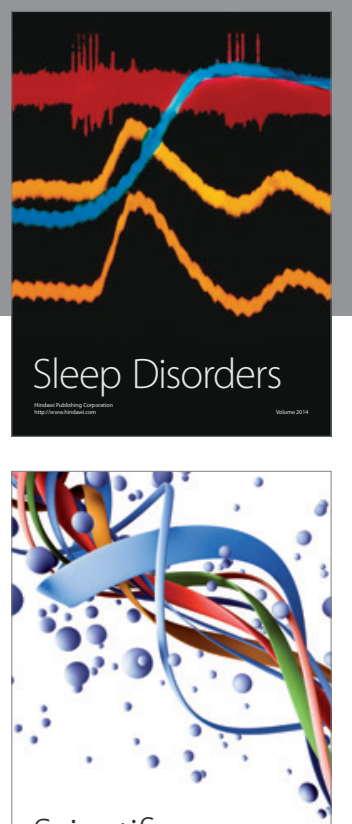

Scientifica
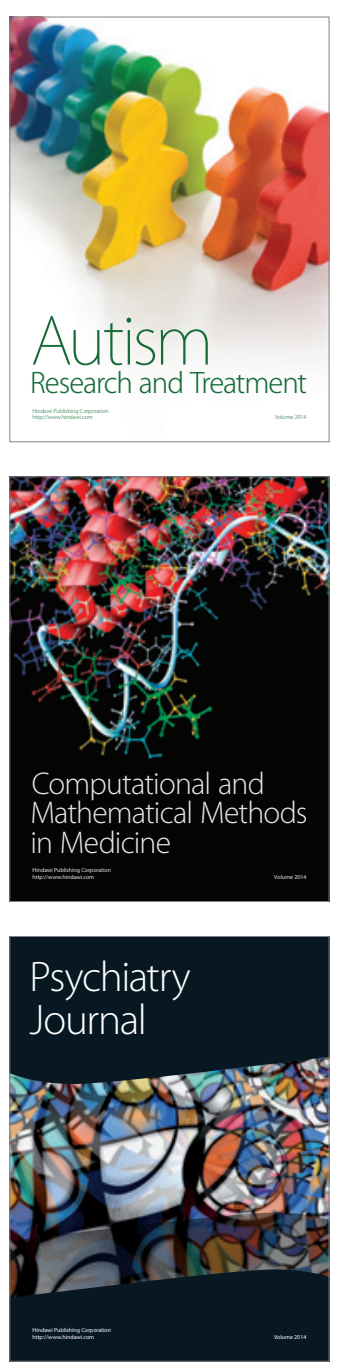
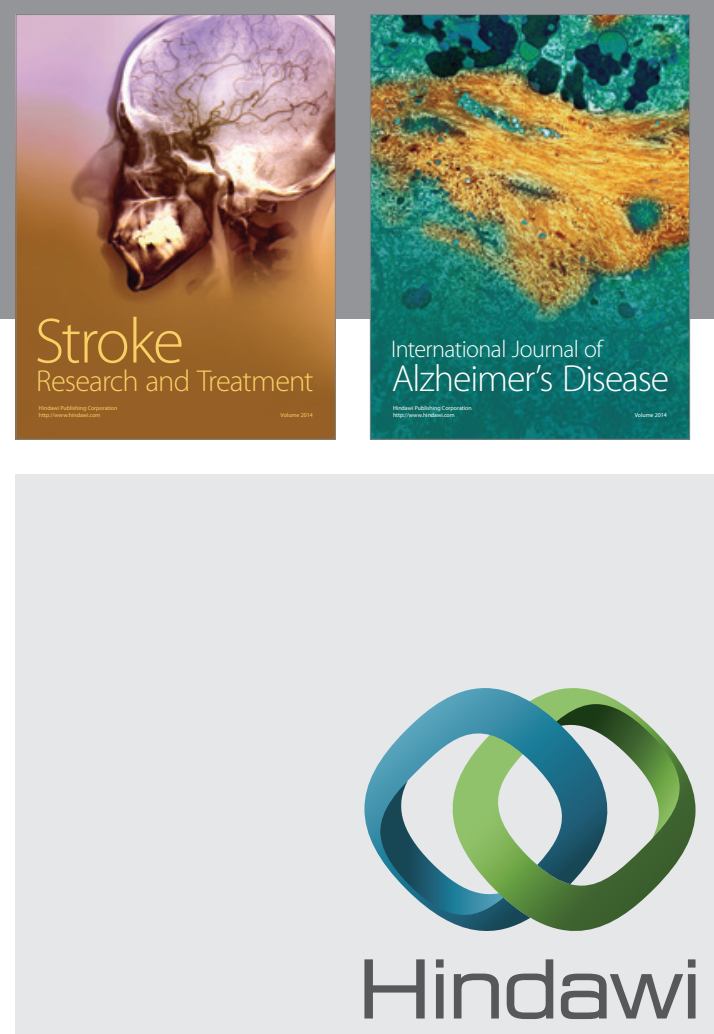

Submit your manuscripts at

http://www.hindawi.com
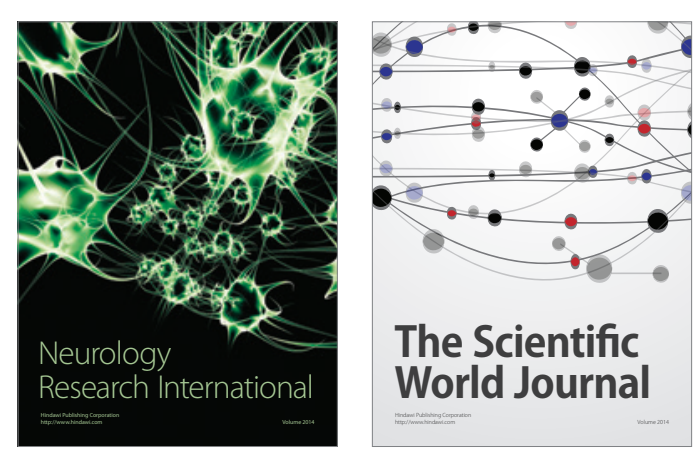

The Scientific World Journal

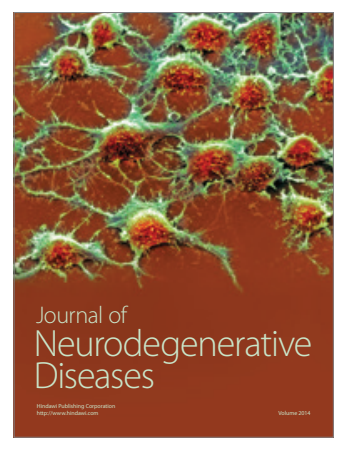

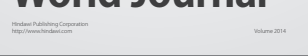

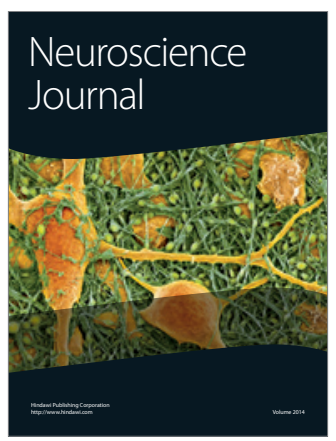

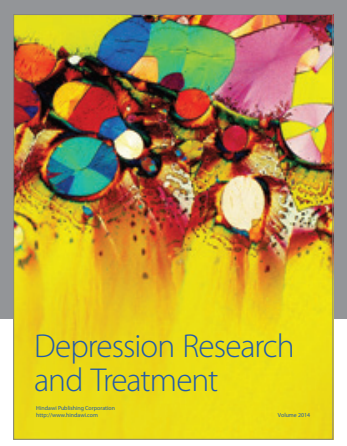
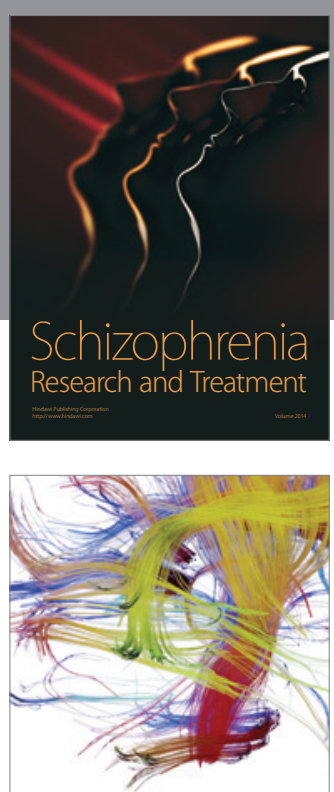

Brain Science

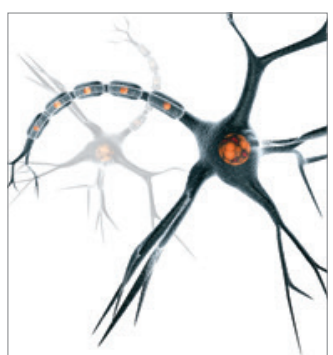

Neural Plasticity
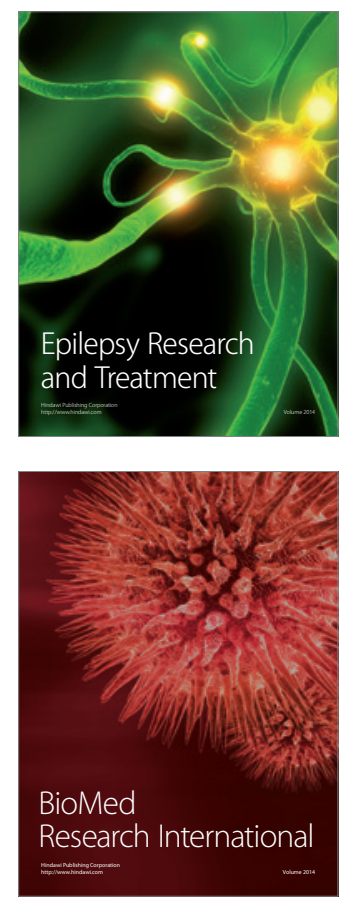

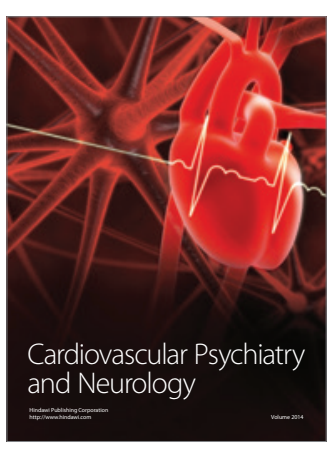

Parkinson's

Disease
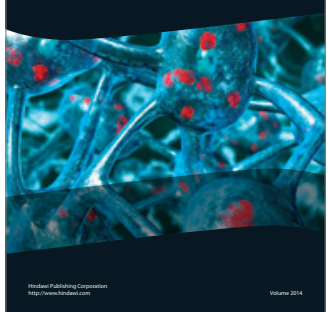